\title{
Women in the media
}

As with everything else in Papua New Guinea, the media work force is male-dominated. However, this pattern is now changing with many more women making a career in communication and gradually moving into middle and senior management.

\section{By ANNA SOLOMON}

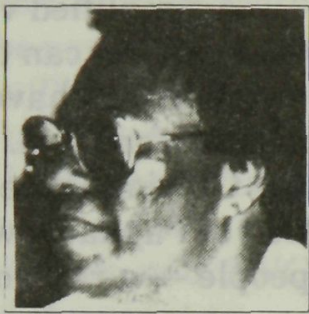

A meeting to discuss Pacific Women in Media, in Apia during September, fell at an opportune time, for Papua New Guinea at least. Work on the National Policy on Information and Communication was completed in December 1993 and copies of the policy paper made available to the public almost a year to the date when the committee was formed in January 1993 to begin the initial work on the policy.

An 80-page document spells out the policy, communication services, information services, information and communication support services, media related policies, the proposed national information and communication council and a code of ethics for the country. The need to set a communication policy, is in part due to the fact that 'not all citizens of the country have an equal opportunity to participate in, and benefit from, the development of the country'. It is an umbrella policy document which attempts to integrate existing and ad hoc information and communication related policies in Papua New Guinea. (National Policy on Information and Communication of Papua New Guinea, December 1993).

However, making this policy work to make access to information easy for the ordinary person, including women, is another big challenge for the formulators of this policy. The National Women's Policy was finally announced last year after initial work began in 1983. This much smaller and more precise document spells out clearly what the government's role and response is to women and development issues. It places responsibility on a number of key government departments to better plan policies so that the impact on women is considered before such activities are implemented. (Papua New Guinea Womens Policy, January 1990). It was developed in recognition of the role of women and their contribution in the development of the nation. The Government developed this policy to create an environment that is conducive to integrating women as both beneficiaries and participants in development.

Interest and debate in the Communication Policy is still very much alive 
Pacific Journalism Review

and on-going, much of that due to the hard-working staff of the Department as well as the media industry itself.

The Women's Policy, on the other hand, has now been documented and that seems to be the end of the issue. It is unlikely that all women's groups throughout the country have access to the policy document. However, that does not mean that they are unaware of the policy.

A simplified version in the two main lingua franca is a big service the Government can do for women who are not literate in English. This is one way they can have access to what the decision makers of the country have in store for them.

Official figures from the 1990 National Census put the female population of Papua New Guinea at 1, 420, 980 out of a population of 2, 978,057 people - a ratio of 110 males per 100 females.

\section{Colonial inheritance}

Papua New Guinea, like most of its Pacific neighbours, inherited its current communications structure from its colonial rulers - in this case, Australia, which in turn is very much influenced by the British press. The print media was the first mass communication medium and was once the privilege of colonisers; they produced the newspapers in their language to meet the demand from their small community. Then the radio followed. And with the passing of time this new means of communication was passed on to the citizens of the country who added new technology and expanded to include TV and many more.

Thus began the birth of the mainstream media in PNG. The electronic media, which is urban based due to the need for a power source, and telecommunications network, is also limited to serving only the main urban areas while limited distribution routes and high illiteracy rate hinder wide circulation of newspapers in the rural areas.

PNG is a male-dominated Melanesian society of 4 million people who speak 869 languages. Thus, one can say it makes sense for the privately owned mass media to publish or broadcast in the official language of government - which is English.

This practice again limits access to information and news by the ordinary citizen of the country who is not literate in English.

The communication network in a country with a very diverse culture and difficult terrain is dominated by radio, the medium that fortunately can reach a far wider audience without huge overheads to the Government, the owner of the National Broadcasting Corporation.

\section{The mainstream media}

Apart from being the cheapest source of disseminating news and information, the Government-owned radio stations also broadcast in the main lingua franca of the provinces, bringing them much closer to being a 
people's medium of mass communication than say TV, the latest to enter the media scene.

Newspapers on the other hand are a very expensive business in PNG. Due to high freight costs charged by the airlines as well as high post office charges, only a limited supply is distributed throughout the country, mostly to the main urban centres.

The three national newspaper groups are based in Port Moresby with two of them operating smaller offices in few provinces. The newspapers are all privately owned: Pacific Star Pty Ltd, which publishes The National, is owned by Malaysian logging giant Rimbunan Hijau; the Post-Courier is one of American Rupert Murdoch's South Pacific Post Pty Ltd's papers; and Word Publishing Pty Ltd, which publishes three weeklies and a monthly The Times of Papua New Guinea, Wantok, Weekend Sports and PNG Business - is owned by the four mainstream churches of the country.

\section{Current ratio of male to female}

As with everything else in PNG, the media work force is male-dominated. However, this pattern is now changing with many more women making a career in communication and gradually moving up to middle management and senior management level.

A case in point is the National Broadcasting Commission. Last year, half the number of reporters in the national newsroom were women (nine out of 16). Of the five executive producer positions, three were held by women - Nicole Johannes in Current Affairs, Kathleen Sakias in Community Programmes and Cathy Goroa in Culture and Entertainment. (Emberson, 1994).

The provincial radio stations are all managed by men although at least three women hold the position of assistant programme managers. The first of these women was appointed in 1986.

The print media has fared a lot better. The three groups now have an increase in female staff both as journalists and support staff. The conservative Murdoch-owned Post-Courier, which until two years ago could only average two female journalists, now employs five.

Word Publishing, on the other hand, which once boasted employing more female journalists than males has seen a drop. It has now evened out so that there are slightly more men (nine) then women (eight) in the Port Moresby office. This provideshealthy competition and equal opportunity in advancing to senior levels. Editors are The Times (female); Wantok (male) Weekend Sports (male) and PNG Business (female). One news editor, Harlyne Joku, and two subeditors are women. The National, the newcomer, at present employs four women out of 14 reporters.

\section{Provincial newspapers}

There are two floundering provincial newspapers, the Madang Watcher 


\section{Pacific Journalism Review}

and Eastern Star. Madang Watcher is edited by a woman, Bertha Somare. The Eastern Star has a female journalist as its senior reporter.

The irregularly published Government-owned newspaper, Hiri Nius, is also edited by a woman, Konio Seneka.

At the provincial level, there is the Government Information Unit, which has a fair representation of women journalists. The provincial radio stations often do not have reporters, those that do would most often have male. One reason for this is the high crime rate in the country, which would make it impossible for young single women living on their own. Often there is no secure housing for these officers and with limited resources, management would give priority to housing a man and his family.

\section{Public Relations}

More women in PNG are now employed in public relations by Government and corporate groups. This is a new area in communication which over the past three years has drawn many young women straight out of journalism school who would otherwise find the news beat of the mainstream media too demanding and less rewarding financially.

The fledgling publishing industry in the country is currently dominated by expatriates. Of the nationals employed in the industry, one female has reached the position of editor - Paruru Lawrence, who edits the Independent Group's monthly business magazine Market Place.

\section{Training}

Women who enter the workforce either train at one of the country's two journalism schools, or are taken on as cadets as was the common practice. Thus, many of them come in with the same attitudes toward news and writing as their male peers. The work place and editorial direction moulds these young women and men into what sort of journalist they end up becoming.

The first six months in the workplace is spent breaking into the news round and establishing contacts. It is also at this time that formal training as well as attitudes to different sections of the community emerges.

\section{Added skills}

One major skill young journalists need to have is the ability to carry out research and to know where to gather information on stories. This need is now recognised by Journalism Studies at the University of Papua New Guinea, thus the move to amalgamate with Library and Information Studies to form the South Pacific Centre for Communication and Information in Development (SPCenCIID) in 1994 so thatjournalists are well versed in information collection and research skills on graduation. This important training must be compul sory for a journalist. Other then general knowledge, it would also equip a reporter to confidently carry out investigative journal-

\section{Page 26}




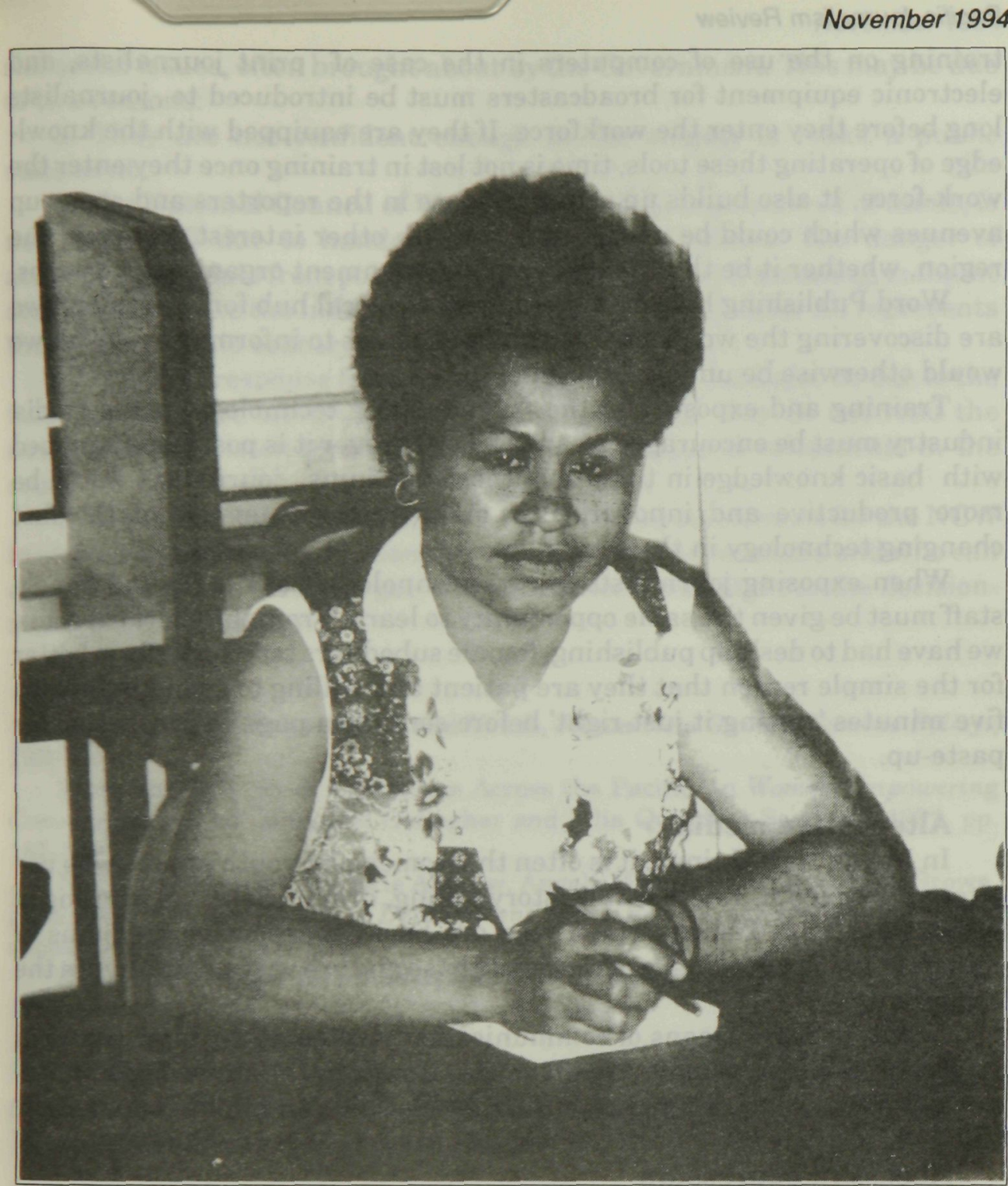

Harlyne Joku, news editor of the Times of PNG, briefs student journalists at the University of PNG about her 1994 environment journalism fellowship to the US.

ism, as well as write on important issues such as the Government's policy on Women and Children. Besides getting background information, facts and figures, it would often turn an otherwise ordinary 'women's story' into a serious, well researched hard hitting news story that would get the attention of the wider community as well as the women.

\section{Adjusting to new technology}

Training in modern technology is also vital. Where possible, hands-on 


\section{Pacific Journalism Review}

training on the use of computers in the case of print journalists, and electronic equipment for broadcasters must be introduced to journalists long before they enter the workforce. If they are equipped with the knowledge of operating these tools, time is not lost in training once they enter the work-force. It also builds up self-confidence in the reporters and opens up avenues which could be used to link-up with other interest groups in the region, whether it be the women, or non-government organisation groups.

Word Publishing has just linked up to the local hub for Pactok and we are discovering the wonders of $\mathrm{E}$-mail and access to information which we would otherwise be unable to obtain.

Training and exposure to the fast changing technology in the media industry must be encouraged at all levels wherever it is possible. Equipped with basic knowledge in the use of these mediums, journalists would be more productive and innovative in making maximum use of the fast changing technology in the workplace.

When exposing journalists to new technology, both male and female staff must be given the same opportunity to learn. From the short exposure we have had to desktop publishing, female subeditors tend to perform better for the simple reason that they are patient and willing to spend that extra five minutes 'getting it just right' before sending a page to production for paste-up.

\section{Alternative media}

In Papua New Guinea, it is often the women and youth groups who use alternative media, whether it be story telling, drama, dancing, printing of posters, leaflets, T-shirts etc. These are basic, inexpensive mediums of communication which have a grassroots base and are very much alive in the community.

Access to these means of communication is often at the inter-personal level compared to the mainstream media. However, they have their limitations - such as lack of finance to pass on the skills and limited audiences.

\section{Access to expression}

Unless there is an active member of the women's groups, most important contributions women make to the community go unreported. Over the past five years, the Women's Division of the Department of Youth and Home Affairs has been conducting small workshops on writing press releases, and informing the media on developments within the women's groups.

If the reports do get into the mainstream media, it would often be by chance rather then pre-planned. Most often, it would be a small photo story from the rural areas or outer provinces. Most of the longer feature material would be about women in the urban area, often the career path of a woman breaking into the male-dominated workforce.

Women leaders do not use the media immediately to react to controver- 
sial social issues, often brought about by the Government. This may be due to two reasons:

1. They are not confident enough in the subject to make a public statement;

2. The National Council of Women, which is always starved of funds, is now better off due to handouts by national politicians. The danger of accepting handouts from politicians, no matter how well-meaning, is that it could compromise the independence of the NCW which after all represents the women of this country.

This lack of response from women leaders again could also be due to the fact that they are often unaware of issues because they do not read the newspapers, or listen to the radio to keep abreast of developments in the country.

If there are funds available, it would be a good investment for the NCW to employ a good media relations person who knows the media and who can effectively use the media to get women's concerns straight to the decisionmakers of this country.

\section{References:}

Department of Home Affairs and Youth, Papua New Guinea Womens Policy., 1990.

Emberson, Jill. 'Bridging Women Across the Pacific,' in Women Empowering Communication, ed. Margaret Gallagher and Lilia Quindoza-Santiago, 1992, pp. 187-209.

Nakikus, Margaret, Marjorie Andrew, Angela Mandie-Filer, Bungtabu Brown, Papua New Guinea: Women in Development Sector Review, United Nations Development Programme, 1991.

National Policy on Information and Communication of Papua New Guinea, 1993.

工ANNA SOLOMON is publisher of Word Publishing and editor-in-chief of the Times of Papua New Guinea. This paper was presented at a PacificWomen in the Media conference in Apia, Western Samoa, 22-25 August 1994. 